\title{
$>$ Correspondências e sinestesias quando Baudelaire aprecia Delacroix
}

\author{
$>$ Correspondences and synesthesias \\ when Baudelaire appreciates Delacroix
}

\section{por Augusto Darde}

Mestre em Literaturas Francesa e Francófonas pelo Programa de Pós-Graduação em Letras da Universidade Federal do Rio Grande do Sul (UFRGS), doutorando em Estudos de Literatura (Sociedade, [Inter]Textos Literários e Tradução nas Literaturas Estrangeiras Modernas) na mesma instituição. Bolsista do Conselho Nacional de Desenvolvimento Científico e Tecnológico (CNPq). E-mail: gugadarde@gmail.com. ORCID: http://orcid.org/0000-0001-7599-1345.

\section{Resumo}

O poeta francês Charles Baudelaire (1821-1867) foi também tradutor, ensaísta e crítico de arte. Em relação à produção poética, é considerado o precursor do simbolismo, a partir da sua obra Les Fleurs du mal, de 1857; na figura do ensaísta, elaborou o conceito de modernidade, referência para a criação artística, os Estudos Literários e a Filosofia. O presente trabalho explora a influência da linguagem poética no seu trabalho de ensaísta e crítico, e vice-versa, buscando compreender a noção das "Correspondências" exposta no poema homônimo do livro de 1857. Analisaremos, com ênfase nos textos sobre a obra do pintor Eugène Delacroix (1798-1863), de que maneira as correspondências e transposições entre pintura, poesia e música já estavam presentes no olhar do jovem crítico de arte.

Palavras-chave: Poesia. Pintura. Correspondências. Sinestesia.

\begin{abstract}
The French poet Charles Baudelaire (1821-1867) was also a translator, essayist, and art critic. In relation to poetic production, he is considered the precursor of symbolism, from his 1857 work Les Fleurs du mal; in the figure of the essayist, he elaborated the concept of modernity, a reference for artistic creation, literary studies and philosophy. The present work explores the influence of poetic language in his essayist and critic work, and vice versa, seeking to understand the notion of "Correspondences" exposed in the homonymous poem of the 1857 book. We will analyze, with emphasis on the texts about the painter Eugène Delacroix (1798-1863), how the correspondences and transpositions between painting, poetry and music were already present in the eyes of the young art critic.
\end{abstract}

Keywords: Correspondences. Poetry. Painting. Synesthesia. 


\section{Introdução}

A primeira atribuição de Charles Baudelaire (1821-1867) é a de poeta, imortalizado pela obra-prima Les Fleurs du mal, de 1857. No entanto, a sua produção poética é consideravelmente reduzida se comparada ao número de trabalhos críticos envolvendo pintura, literatura e música, além dos ensaios filosóficos sobre a criação artística e a estética moderna. De todo modo, o olhar do poeta aparece na pluma do jornalista, do crítico e do filósofo. Mecanismos estilísticos e figuras de linguagem respondem a um amplo fundamento estético permeando todo o percurso do escritor.

O presente trabalho irá explorar as origens dessa estética e explicitar como ela já se encontra, de certa maneira, sistematizada nos primeiros textos críticos sobre a obra de Eugène Delacroix (1798-1863), apresentando analogias entre literatura, pintura e música.

Começaremos falando sobre a formação inicial de Baudelaire, os anos de dandismo e as condições práticas do seu métier de homem de letras, até a época de publicação das Fleurs du mal. Em seguida, analisaremos o soneto "Correspondances" para compreender o modelo estético diluído em sua obra e mesmo na de outros artistas, abordando heranças que o texto retoma. Para concluir, traremos a crítica a Delacroix, observando como é articulada a transposição das diferentes expressões artísticas.

\section{Vida e obra até Les Fleurs du mal}

É relevante observar que Charles Baudelaire tinha 36 anos ao publicar o seu principal livro, o primeiro de poesia, idade que representa certa maturidade 
para uma estreia. Mas alguns dos títulos presentes nas Fleurs du mal já haviam sido escritos pelo menos doze anos antes de sua organização em obra. Um tal hiato de tempo nos sugere muito sobre o percurso de criação e as condições de produção.

Baudelaire iniciaria a carreira de escritor como crítico de arte. Antes de publicar, já atraía a atenção dos ex-colegas do lycée Louis-le-Grand e dos primeiros companheiros de boemia literária. Escrevia poemas, adquiria muitos livros de filosofia e arte, dividia seu tempo entre museus, bibliotecas, consumo de vinho e haxixe nos arredores da Sorbonne. Já esboçava uma vida de dandy aos 18 anos, vivendo Paris "[...] como se a fortuna fosse ilimitada" ${ }^{1}$, determinado a ser poeta, contrariando os anseios da mãe e do padrasto, que lhe planejavam uma carreira diplomática. Em junho de 1841, alarmados pelo desregramento do filho, o casal Aupick embarca Baudelaire numa longa viagem, imaginando que o veriam arrependido e comportado ao retorno. Em 3 meses, o jovem de 20 anos chega às Ilhas Maurício, depois à Ilha da Reunião. Mas interrompe o périplo, sentindo falta de sua Paris. Em fevereiro de 1842, está de volta à capital francesa.

Fará novas amizades literárias, dentre as quais Théophile Gautier e Théodore de Banville. Deixa a casa dos pais para habitar, em meses, diferentes apartamentos na Île Saint-Louis: "Baudelaire se apraz entre os pintores e comerciantes de antiguidades que habitam nesse microcosmo magnificamente construído"2 . A vida de dandy se confirma e intensifica: compra móveis, objetos e quadros antigos para decorar o apartamento do Quai d'Anjou. Da época, é

\footnotetext{
1 “[...] comme si sa fortune était illimité." André Guyaux, Le Paris de Baudelaire, 2017, p. 22. Todas as citações cujo idioma original é o francês foram por mim traduzidas em português.

2 "Baudelaire se plaît parmi les peintres et brocanteurs qui habitent ce microcosme magnifiquement bâti." Ibidem, p. 26.
} 
icônico o seu retrato feito em 1843 pelo amigo pintor Émile Deroy (1820-1846). Recebe visitas como um verdadeiro aristocrata, exige as melhores mesas nos restaurantes. Cria um museu particular, no qual constam as doze litografias de Hamlet, originais de Delacroix. As coleções antigas da biblioteca surpreendem os convidados. O aluno insubordinado e medíocre do lycée Louis-le-Grand torna-se um intelectual autodidata, honnête homme anacrônico, nutrindo sem limites uma ilustração em torno das artes. Daí surgirá o grande crítico.

Charles Asselineau, amigo no auge do período dandy e quem publicaria uma biografia dois anos após a morte de Baudelaire, testemunha que, na década de 1840, ocorreu uma evolução no espírito público com o final das batalhas literárias: "Victor Hugo, então incontestável, prosseguia seu triunfo [...]. O interesse, que sempre abandona as causas ganhas, virou-se para outro lado: a Pintura destronou a Poesia"3. O gênio de Delacroix se impunha, reunindo em torno dele críticos ferozes e defensores apaixonados. Baudelaire aproveitaria a oportunidade para tomar partido a favor da mão que pintou La Liberté guidant le peuple.

Mas ainda será preciso refinar o olhar do crítico. Os anos de 1843 e 1844 acumulam recusas de artigos, pelas mais diversas revistas e jornais, "[...] que os julgam passíveis de melhora ou manchados de imoralidade", além de "audaciosos demais na sátira" ${ }^{4}$. Às negativas, somam-se as dívidas. No período entre 1844 e 1846, a atividade epistolar de Baudelaire é marcada por solicitações

\footnotetext{
3 “Victor Hugo, déformais incontefté, confacrait fon triomphe [...]. L'intérêt, qui toujours déferte les caufes gagnées, fe tourna d'un autre côté : la Peinture détrôna la Poéfie." Charles Asselineau, Charles Baudelaire, sa vie et son œuvre, 1869, p. 15.

4 “[...] qui les jugent passibles de poursuite ou entachés d'immoralité / trop audacieux dans la satire." Pascal Pia, Baudelaire, 1995, p. 180.
} 
de empréstimos ou pedidos de alongamento de prazos para pagamentos. Paralelamente às dificuldades materiais, observa-se um esforço do jovem em afirmar à mãe que pode sobreviver como escritor.

Finalmente, publica o Salon de 1845 daquele ano, primeiro texto assinado, brochura de 72 páginas em que já constam elogios a Delacroix. No mês seguinte, o soneto "À une créole", que estará nas Fleurs du mal, é publicado em L'Artiste. Apesar do triunfo inicial, em junho do mesmo ano, Baudelaire tenta cometer suicídio, deixando uma triste carta de testamento relatando os problemas com dívidas, além do esforço para provar a sanidade mental e garantir que os seus poucos bens passem a Mademoiselle Lemer, companheira à época. Mas o poeta, felizmente, falha no plano e sobrevive. Lança, no ano seguinte, o Salon de 1846. A situação financeira melhora relativamente: colabora em diversos jornais, publicando, periodicamente, artigos e poemas esparsos.

Em 1848, sai o primeiro conto traduzido de Allan Poe. O editor Michel Lévy anuncia, para 1849, o lançamento de um livro de poemas de Baudelaire: Les Limbes, que será concretizado apenas em 1857, por outro editor e com o título Les Fleurs du mal. O anúncio irrealizado nos testemunha uma instabilidade do mercado editorial, particularmente em relação à publicação de poesia.

A Monarchie de Juillet (1830-1848) é um período importante na reformulação do gênero poético e da própria noção de literatura. José-Luis Diaz nos relata que, à época, literatura e poesia são até mesmo opostas: “[...] à literatura, que é considerada então como coisa impura, trivial, troca social, negócio de instituição, de tradição e trabalho, opõe-se a 'poesia', miragem de uma 
palavra ao mesmo tempo solitária e celeste" ${ }^{5}$. Ainda sob herança da filosofia iluminista, literatura é o domínio enciclopédico, como artigos e ensaios em prosa, enquanto a poesia compreende o mais alto e isolado nível do terreno da criação artística. Um tal status da poesia acaba refletido no mercado editorial, situação que se prolonga. Em suma, poesia não vende, não atrai a grande massa de leitores. Para sobreviver, Baudelaire faz literatura, não poesia. É ilustrativo o prefácio da peça Chatterton, de 1835, em que Vigny culpa a sociedade por desconhecer o papel sagrado do poeta e ser indiferente à sua miséria: “Vocês não estão escutando esses jovens desesperados que pedem o pão cotidiano, e de quem ninguém paga o trabalho? [...] Só lhe são necessárias duas coisas: a vida e o devaneio; o PÃO e o TEMPO"6.

Para Baudelaire, o início da década de 1850 será marcado pela publicação de ensaios importantes, como Du vin et du haschisch (1851), além de Morale du joujou (1853) e De l'essence du rire (1855). Também retorna à crítica com Exposition universelle (1855). É lançada, ainda, a tradução integral das Histoires extraordinaires (1856), de Allan Poe.

Foi um longo caminho até chegar à obra-prima, ou à confirmação da atribuição definitiva de poeta. De qualquer maneira, a versatilidade da pluma não representa um defeito aos olhos do próprio Baudelaire: “Tenho pena dos poetas a quem apenas o instinto guia; eu os acho incompletos [...]. Seria prodigioso que

\footnotetext{
5 “[...] à la littérature, qui est pour l'instant considérée comme chose impure, triviale, affaire sociale, affaire d'institution, de tradition et de métier, s'oppose la "poésie», mirage d'une parole à la fois solitaire et céleste." José-Luis Diaz, "L'autonomisation de la littérature (1760-1860)", 2001, p. 16.

6 "N'entendez-vous pas ces jeunes désespérés qui demandent le pain quotidien, et dont personne ne paye le travail ? [...] Il ne lui faut que deux choses: la vie et la rêverie; le PAIN et le TEMPS." Alfred de Vigny, Chatterton, 1968, p. 32.
} 
um crítico se tornasse poeta, e é impossível que um poeta não contenha um crítico"7. Veremos que a escrita do crítico, desde os primeiros textos, confundese com um certo olhar poético.

\section{As Correspondances}

Se os escritos de Baudelaire parecem orbitar em torno das Fleurs du mal, os poemas ilustrando o que propôs em ensaios e críticas, o soneto "Correspondances" pode ser tido como o resumo de uma estética, a qual guiará uma nova tendência em poesia, o simbolismo. Marcel Raymond observa que não podemos falar em escola simbolista, já que simbolismo evoca um universo espontâneo, “[...] ao qual a razão ou diversos órgãos de censura, nas sociedades modernas, vêm fazer obstáculo, mas que funciona quase em controle nos 'primitivos' ou durante o sonho"8. Portanto, simbolismo é, antes de tudo, uma disposição humana e atemporal. Durante boa parte da segunda metade do século XIX, os poetas francesas irão explorar essa disposição com grande ênfase, e até mesmo verão nela um pressuposto básico da linguagem poética.

Os dois primeiros quartetos de "Correspondances"9 são fundamentais para a presente análise:

A Natureza é um templo onde vivos pilares

\footnotetext{
7 “Je plains les poètes que guide le seul instinct; je les crois incomplets [...]. Il serait prodigieux qu'un critique devînt poète, et il est impossible qu'un poète ne contienne pas un critique." Charles Baudelaire, Critique d'art, 2011, p. 453.

8 “[...] auquel la raison ou divers organes de censure, chez les civilisés, viennent faire obstacle, mais qui fonctionne presque sans contrôle chez les "primitifs» ou pendant le rêve." Marcel Raymond, De Baudelaire au Surréalisme, 1940, p. 49.

${ }^{9}$ A tradução em português dos poemas neste artigo foi feita de maneira literal, não atentando aos aspectos de versificação, buscando priorizar os elementos lexicais e temáticos.
} 
Deixam, às vezes, escapar confusas falas;

O homem aí passa através de florestas de símbolos

Que o observam com olhares familiares.

Como longos ecos que, de longe, se confundem

Em uma tenebrosa e profunda unidade,

Vasta como a noite e como a claridade,

Os perfumes, as cores e os sons se respondem ${ }^{10}$.

Temos, já nos dois primeiros versos da estrofe inicial, elementos importantes da estética simbolista: a marcação do espaço natural e a atribuição de uma faculdade comunicativa a esse mesmo espaço, através do emprego da figura de personificação que lhe concede a fala. Desde já, notemos, as "falas" são "confusas", o que as enquadra distante da ordem, da medida regular, da precisão, aproximando-as da desordem característica do sonho, como aponta Raymond. Os dois versos seguintes posicionam o ser humano no espaço da introdução, agora caracterizado por "florestas de símbolos", e mais uma personificação dá à natureza a capacidade da observação, do olhar. Em suma, o primeiro quarteto marca uma possibilidade de comunicação entre homem e "Natureza" - em letra maiúscula, reforçando o caráter alegórico -, trazida pela fala e pela visão, permeada por símbolos.

O primeiro verso do segundo quarteto, fundado na sonoridade dos "ecos", mescla as amplitudes temporal e espacial destes, respectivamente através dos adjetivos "longos" e "longe". O verbo reflexivo "se confundem" pode tanto retomar o sentido de "olhares familiares" quanto reforçar o adjetivo das

\footnotetext{
10 "La Nature est un temple où de vivants piliers / Laissent parfois sortir de confuses paroles; /L'homme y passe à travers des forêts de symboles / Qui l'observent avec des regards familiers. / Comme de longs échos qui de loin se confondent / Dans une ténébreuse et profonde unité, / Vaste comme la nuit et comme la clarté, / Les parfums, les couleurs et les sons se répondent." Charles Baudelaire, Les Fleurs du mal, 2012, p. 33.
} 
"confusas falas" da estrofe precedente. O terceiro e o quarto versos do segundo quarteto são construídos em torno da ideia de "unidade", que é plena de qualidades: "tenebrosa", "profunda", "vasta", sendo este último adjetivo detalhado nas metáforas "como a noite e como a claridade", a vastidão, assim, fundada entre polos contrários e referentes ao sentido da visão. A preposição "Em", do segundo verso do quarteto, faz da "unidade" a estrutura na qual se desenrola a comunicação sugerida no primeiro e no quarto versos. Este último, aliás, apresenta a figura de linguagem fundamental do simbolismo: a sinestesia, que possibilita a "perfumes", "cores" e "sons" se comunicarem, diferentes sentidos interagirem. É também no último verso do segundo quarteto que temos uma comunicação efetiva através do verbo reflexivo "se respondem"; no primeiro quarteto, ainda não havia comunicação, só conhecemos ali a sua possibilidade. Uma interlocução entre homem e "Natureza", por meio de uma linguagem confusa, em profunda unidade, consuma-se no segundo quarteto.

Os dois tercetos do soneto não trazem grande novidade ao que já foi exposto nos quartetos: eles desenvolvem exemplos dos perfumes "Que cantam os transportes do espírito e dos sentidos" ${ }^{11}$. Veremos adiante que, para Baudelaire, também bastam os quartetos de "Correspondances" para elucidar uma estética e/ou uma metafísica.

\subsection{Ecos românticos, entre outras distâncias}

O simbolismo poderia ser resumido numa expansão da linguagem, esta indo muito além dos idiomas com suas gramáticas e convenções próprias, isto é,

11 "Qui chantent les transports de l'esprit et des sens." Ibidem. 
a linguagem dos símbolos transgride a linguagem dos signos linguísticos, e o acesso a uma tal expansão se dá através da constatação de que os sentidos podem se mesclar sinestesicamente, perfumes tendo cor, sons tendo cheiro, entre outras combinações. A fundação dessa comunicação se dá entre ser humano e natureza, como se a consciência percebesse uma unidade com a sua origem primitiva.

Mas não foi Baudelaire o precursor da ideia das correspondências, a unidade e comunicação entre ser e natureza. Jean-Jacques Rousseau, na célebre "Cinquième Promenade" das Rêveries du promeneur solitaire, escritas entre $1776 \mathrm{e}$ 1778, já descrevia-nos um momento de interação:

\begin{abstract}
Saindo de um longo e doce devaneio, vendo-me envolto de verde, de flores, de pássaros e deixando errarem meus olhos ao longe sobre as romanescas margens que bordam uma vasta extensão de água clara e cristalina, eu assimilava a minhas ficções todos esses amáveis objetos e, encontrandome enfim gradualmente de volta a mim e ao que me envolvia, eu não podia marcar o ponto de separação entre as ficções e as realidades, de tanto que tudo concorria igualmente a me fazer cara a vida recolhida e solitária que eu levava nessa bela estadia ${ }^{12}$.
\end{abstract}

A impossibilidade de marcar o ponto de separação entre as "ficções" desse homem que passeia e os objetos externos a ele, essa diluição da imaginação e da natureza remetem-nos à unidade das correspondências. Também

\footnotetext{
12 “En sortant d'une longue \& douce rêverie, en me voyant entouré de verdure, de fleurs, d'oiseaux \& laissant errer mes yeux au loin sur les romanesques rivages qui bordoient une vaste étendue d'eau claire $\&$ cristalline, j'assimilois à mes fictions tous ces aimables objets, \& me trouvant enfin ramené par degrés à moi-même \& à ce qui m'entourait, je ne pouvois marquer le point de séparation des fictions aux réalités, tant tout concouroit également à me rendre chere la vie recueillie \& solitaire que je menois dans ce beau séjour." Jean-Jacques Rousseau, Les Rêveries du promeneur solitaire, 1782, p. 117.
} 
Chateaubriand, no Génie du christianisme, de 1802, reserva um lugar fundamental ao espaço natural para a reflexão:

Há, no homem, um instinto que o coloca em relação com as cenas da natureza. Ah! quem não passou horas inteiras sentado, sobre a margem de um rio, a ver correrem as ondas! Quem não sentiu prazer, à beira do mar, ao observar esbranquiçando o coral distante! [...] essa imensidão que faz nascer em nós um vago desejo de deixar a vida para abraçar a natureza e nos confundir com seu autor ${ }^{13}$.

Na sua versão das correspondências, Chateaubriand explora e define claramente uma metafísica: se a natureza é um canal de comunicação com a origem, essa origem é divina, ligada ao Deus cristão. Assim será igualmente em Victor Hugo, poeta de uma geração em que a estética romântica já está estabelecida - e mesmo em vias de se tornar antiquada. Num poema das suas Contemplations, de 1856, a beleza natural é uma oração, curva-se a Deus e não deixa de causar inveja a quem dela está excluído:

Oh, encostas! oh, vales! sopros, suspiros, respirações!

A hosana das florestas, dos rios e das planícies,

Se eleva gravemente a Deus, pai do dia;

E todas as brancuras são estrofes de amor;

$[\ldots]$

O infinito todo em êxtase se eleva.

$\mathrm{E}$, enquanto isso, Satã, o invejoso, sonha ${ }^{14}$.

\footnotetext{
13 "Il y a dans l'homme un instinct qui le met en rapport avec les scènes de la nature. Eh! qui n'a passé des heures entières assis, sur le rivage d'un fleuve, à voir s'écouler les ondes! Qui ne s'est plu, au bord de la mer, à regarder blanchir l'écueil éloigné! [...] cette immensité qui fait naître en nous un vague désir de quitter la vie pour embrasser la nature et nous confondre avec son auteur." F. -R. De Chateaubriand, Génie du christianisme, 1828, p. 223.

14 “Ô coteaux! ô sillons! souffles, soupirs, haleines! / L'hosanna des forêts, des fleuves et des plaines, / S'élève gravement vers Dieu, père du jour; / Et toutes les blancheurs sont des strophes d'amour; [...] L'infini tout entier d'extase se soulève. / Et, pendant ce temps-là, Satan, l'envieux, rêve." Victor Hugo, Les Contemplations, 2010, p. 17.
} 
Eis aí uma ruptura entre a correspondência romântica e a simbolista: se os românticos não hesitam em afirmar a natureza como criação de Deus, Baudelaire opta por não expor com clareza a metafísica dessa origem, centrando-se em afirmar a existência de um canal de comunicação entre homem e natureza, explorando os efeitos da sinestesia. Enquanto a estética romântica expressa uma clara revelação metafísica, o simbolismo do poema "Correspondances" guarda a sugestão sobre a completude da "unidade", culminando num efeito de mistério. ${ }^{15}$ O interesse de Baudelaire é a expansão da linguagem e da imaginação, não uma afirmação moral, o que se confirma no ensaio Théophile Gautier (1859): “Gautier é o amor exclusivo do Belo"16, desligando o Belo da tríade antiga do Bom-BeloVerdadeiro, ainda sustentada por Victor Hugo no ensaio William Shakespeare (1864), sendo o Bem a moral cristã. A nova nuance em Baudelaire não impedirá, entretanto, que poetas de inspiração simbolista confiram um fundo religioso - e ocidental - às suas metafísicas, como Théodore de Banville ou Paul Claudel.

É importante acrescentar que a unidade das correspondências não são, tampouco, criação dos românticos. Estes herdam do panteísmo de Spinoza, que nega a separação mecanicista entre Deus e natureza em Descartes, afirmando que “[...] a Natureza (ou a Substância, ou Deus - termos equivalentes no sistema), realidade absolutamente infinita, se exprime em uma infinidade de atributos" ${ }^{17}$, ou mesmo da ideia renascentista do homem tido como o microcosmo de um

\footnotetext{
${ }^{15}$ A prevalência da sugestão, do obscurantismo, da dissonância, aliás, são características da lírica moderna, segundo Hugo Friedrich: "observamos nela a tendência de manter-se afastada o tanto quanto possível da mediação de conteúdos inequívocos". Hugo Friedrich, Estrutura da lírica moderna: da metade do século XIX a meados do século XX, 1978, p. 16.

16 "Gautier, c'est l'amour exclusif du Beau." Charles Baudelaire, Théophile Gautier, 1859, p. 38.

17 “[...] la Nature (ou la Substance, ou Dieu - termes équivalents dans le système), réalité absolument infinie, s'exprime en une infinité d'attributs." Charles Ramond, "Les Philosophies et la Nature au XVIIe siècle", 2002, p. 83.
} 
macrocosmo, unidade íntima que visa a “[...] posicionar a eminente dignidade do homem no universo, ao mesmo tempo em que fornece um princípio, um eixo de análise, de descrição, fazendo-se cada vez mais concreta"18.

Em seu detalhado estudo sobre os românticos alemães, que declaram a influência spinozista, Albert Béguin reflete sobre o retorno cíclico dessas ideias: “[...] parece que o pensamento humano deve, periodicamente, revigorar-se para corrigir o racionalismo puro"19. O simbolismo, no sentido atribuído por Marcel Raymond, enquadra-se perfeitamente na remota linha de pensamento que prefere negar ou questionar os impérios do racionalismo.

\subsection{Correspondências entre as artes}

Baudelaire não escreveu um Art poétique ou algo similar a um manual de escrita poética. ${ }^{20}$ No entanto, a sua perspectiva estética foi exposta de maneiras diversas, principalmente através do elogio a artistas que apresentavam obras contendo os seus critérios enquanto poeta. Os exemplos dos principais mestres ou aliados - são Eugène Delacroix, Théophile Gautier - a quem Baudelaire dedica as Fleurs du mal -, Edgar Allan Poe, Richard Wagner e Constantin Guys. Veremos que não há incoerência alguma no fato de constarem nessa lista, além de escritores, dois pintores e um músico.

18 “[...] devient une manière de poser l'éminente dignité de l'homme dans l'univers, en même temps qu'elle fournit un principe, un axe à l'analyse, à la description, qui se fait de plus en plus concrète." Henri Mitterand, Littérature: Textes \& documents XVIIe siècle, 1987, p. 216.

19 “[...] il semble que la pensée humaine doive périodiquement se retremper pour corriger le rationalisme pur." Albert Béguin, L'Âme romantique et le rêve, 1993, p. 67.

${ }^{20}$ Os seus Conseils aux jeunes littérateurs (1846) não configuram um manifesto poético. O texto reúne dicas de sobrevivência, plenas de ironia, aos que pretendem se aventurar no terreno literário. 
A liberação da linguagem que o simbolismo das correspondências proporciona, apesar de ter surgido na perspectiva de unidade entre homem e natureza, não se limita a essa relação fundadora:

Baudelaire não concebe a poesia como diferindo, em sua natureza, da pintura ou da música: ele vê ao contrário, nessa unidade poética das linguagens tecnicamente diferentes, uma aplicação e uma confirmação de sua estética da analogia e da correspondência: não são somente os perfumes, as cores e os sons que se respondem, são também as artes elas mesmas, as cores da pintura, os sons da música, as sílabas, os ritmos e as "alegorias" da poesia ${ }^{21}$.

A ideia remonta, mais uma vez, ao romantismo. Nesse caso, à noção de Ars una dos românticos de Jena - Schiller, os irmãos Schlegel, Novalis, entre outros , que pretendiam a convergência ou síntese dos diversos modos de expressão. A tendência é especialmente sensível em Novalis, que, em 1798, propôs um novo idealismo e uma obra enciclopédica:

[...] o estado mágico consiste na capacidade de "romantizar o mundo", de reconciliar o corpo e o espírito, a Natureza e o Eu [...]. No mesmo tempo da descoberta do idealismo mágico, nasce o projeto de uma grande Enciclopédia do mundo visível e invisível. E, ainda hoje, não saberíamos ler verdadeiramente a obra de Novalis sem a reinscrever nessa perspectiva [...]. Encontramos aí sem dúvida, pela primeira vez, o projeto de uma obra

21 "Baudelaire ne conçoit pas la poésie comme différant dans sa nature de la peinture ou de la musique: il voit au contraire, dans cette unité poétique des langages techniquement différents, une application et une confirmation de son esthétique de l'analogie et de la correspondance: ce ne sont pas seulement les parfums, les couleurs et les sons qui se répondent, ce sont aussi les arts eux-mêmes, les couleurs de la peinture, les sons de la musique, les syllabes, les rythmes et les 'allégories' de la poésie." Henri Lemaitre, La Poésie depuis Baudelaire, 1965, p. 22. 
de arte total (Gesammtkunstwerk) que assombrará os românticos até Wagner ${ }^{22}$.

No texto crítico Richard Wagner et Tannhäuser à Paris, de 1861, Baudelaire relata o grande rumor causado pela encenação da ópera do compositor alemão na capital francesa em 1860. Trinta anos após a Bataille d'Hernani, que havia dividido clássicos e românticos em torno do teatro de Victor Hugo, o acontecimento atesta um prolongamento da forte resistência francesa a modificações em paradigmas clássicos. No caso de Wagner, a ópera. Sua ousadia foi fundir poesia e música, escrevendo os próprios libretos, chamando os textos de poemas. A terceira parte de seu extenso ensaio Ópera e Drama, de 1851, é intitulada "A poesia e a música no drama do futuro"; ao falar da figura do músico e do poeta em seus respectivos trabalhos, afirma que “[...] se, no sacrifício que eles trazem um ao outro, com seu poder mais elevado, eles se confundem reciprocamente um no outro - então, o Drama nasce em sua plenitude"23. O ponto de partida da ópera wagneriana é a fusão entre poesia e música, não um enquadramento na tradição formal do gênero. Nessa união, cuja síntese é o "Drama", ecoa tanto o projeto de Novalis quanto a tragédia grega, que também aliava diferentes artes, influência antiga de Wagner elucidada por Baudelaire.

\footnotetext{
22 “[...] l'état magique consiste dans la capacité a 'romantiser le monde', à reconcilier le corps et l'esprit, la Nature et le Moi [...]. En même temps que la découverte de l'idéalisme magique, naît le projet d'une grande Encyclopédie du monde visible et invisible. Et aujourd'hui encore, on ne saurait lire véritablement l'œuvre de Novalis sans la réinscrire dans cette perspective. [...] On trouve là sans doute pour la première fois le projet d'une œuvre d'art totale (Gesammtkunstwerk) qui hantera les romantiques jusqu'à Wagner." Philippe Boyer, Le romantisme allemand, 1985, p. 70 .

23 “[...] si, dans le sacrifice qu'ils apportent l'un à l'autre, de leur pouvoir le plus élevé, ils se confondent réciproquement l'un dans l'autre - alors, le Drame naît dans sa plénitude." Richard Wagner, Euvres en prose de Richard Wagner, 1913, p. 245.
} 
O poeta francês ironiza a surpresa do público parisiense ante as correspondências propostas no Tannhäuser, completando: “[...] realmente surpreendente seria se o som não pudesse sugerir a cor, que as cores não pudessem dar a ideia de uma melodia, e que o som e a cor fossem impróprios a traduzir ideias" 24 . Poucas linhas depois, transcreve as duas primeiras estrofes do soneto "Correspondances", encontrando em sua própria criação a legitimação estética de Wagner. Desenvolve-se aí um Art poétique implícito: se Nicolas Boileau é explícito ao cantar, em alexandrinos, como escrever bons alexandrinos, Baudelaire indica num gênio que admira os preceitos do que também elabora enquanto esteta. É igualmente exemplar o caso do ensaio sobre Constantin Guys: discorrendo sobre a obra do pintor, Baudelaire irá desenvolver o seu conceito de modernidade. Curiosamente, crítico e objeto da crítica, como que por correspondências, se respondem através da unidade da arte.

A figura do artista, tanto quanto a sua criação, ocupa grande espaço nos textos críticos de Baudelaire. Há, seguidamente, a constatação de uma limitação em utilizar um só termo para definir aqueles cuja obra admira. Assim, caracteriza-os em conceitos híbridos: Richard Wagner é um músico-poetadramaturgo ${ }^{25}$; Constantin Guys, o pintor da vida moderna, é um artista-filósofo ${ }^{26}$;

\footnotetext{
24 “[...] ce qui serait vraiment surprenant, c'est que le son ne pût pas suggérer la couleur, que les couleurs ne pussent pas donner l'idée d'une mélodie, et que le son et la couleur fussent impropres à traduire des idées." Charles Baudelaire, Critique d'art, 2011, p. 444.

25 “[...] não é surpreendente que os homens de letras, em particular, tenham-se mostrado simpáticos por um músico que se glorifica de ser poeta e dramaturgo." / "[...] il n'est pas étonnant que les hommes de lettres, en particulier, se soient montrés sympathiques pour un musicien qui se fait gloire d'être poète et dramaturge." Ibidem, p. 467.

26 "Observador, flâneur, filósofo, chame-o como quiser." / "Observateur, flâneur, philosophe, appelez-le comme vous voudrez." Ibidem, p. 347.
} 
Edgar Allan Poe, comparado a Delacroix, é um escritor-colorista ${ }^{27}$, concebendo, ao mesmo tempo, o pintor como poeta. Se Théophile Gautier não é referido como dominando outra arte além da escrita, ele é provido de "uma imensa inteligência inata da correspondência e do simbolismo universais, esse repertório de toda metáfora" ${ }^{28}$.

Testemunhamos, assim, que as transposições das correspondências permeiam o olhar de Baudelaire em diferentes épocas, excedendo a produção poética.

\section{Correspondências e sinestesias ao apreciar Delacroix}

A nossa escolha em aprofundar a crítica sobre Delacroix foi, antes de tudo, pela presença do pintor já nas primeiras publicações - e elogios fartos - de Baudelaire enquanto crítico. Analisaremos trechos do Salon de 1845 e do Salon de 1846, observando que a estética das correspondências já figura nesses trabalhos. Da primeira obra, iremos examinar comentários das telas apresentadas; da segunda, explicitaremos a formulação teórica feita pelo escritor, percebendo que, em ambos os casos, a figura de Delacroix é central.

O evento do Salon de peinture et de sculpture remonta ao século XVII, sob Louis XIV, no contexto do surgimento das Académies reais. Sofreu mudanças

\footnotetext{
27 “Como nosso Eugène Delacroix, que elevou sua arte à altura da grande poesia, Edgar Poe gosta de agitar suas figuras sobre fundos violáceos e esverdeados onde se revelam a fosforescência da podridão e o cheiro da tempestade." / "Comme notre Eugène Delacroix, qui a élevé son art à la hauteur de la grande poésie, Edgar Poe aime à agiter ses figures sur des fonds violâtres et verdâtres où se révèlent la phosphorescence de la pourriture et la senteur de l'orage." Charles Baudelaire, "Edgar Poe, sa vie et ses oeuvres", 1875, p. 30.

28 "[...] une immense intelligence innée de la correspondance et du symbolisme universels, ce répertoire de toute métaphore." Charles Baudelaire, Théophile Gautier, 1859, p. 40.
} 
estruturais no decorrer do tempo, devido às diversas sucessões de regime político na França a partir da Revolução. As edições anuais do Salon se estabeleceram do período da Restauração até 1880 . A crítica de arte em torno do evento atestou um verdadeiro gênero literário, “[...] que ocupa a cada primavera as colunas ou os folhetins dos jornais e se apresenta em formato de brochura nas vitrines dos livreiros" 29 . O gênero também se mostra como plataforma de embates estéticos.

\subsection{Romantismo e teoria da cor}

As motivações técnicas do elogio a Delacroix são esquissadas por Baudelaire desde o Salon de 1845, mas sem grande sistematização. Ao discorrer sobre a cor "incomparável" e a "perfeição" do quadro Dernières paroles de MarcAurèle, explica: "O público tem ideia da dificuldade em modelar com a cor? A dificuldade é dupla [...], encontrar, de início, a lógica das sombras e da luz, em seguida, a justeza e a harmonia do tom" ${ }^{30}$. O leitor compreende que Delacroix, segundo Baudelaire, domina a arte de desenhar com a cor.

É na introdução do Salon de 1846 que o crítico se estenderá sobre os fundamentos teóricos justificando o seu juízo das obras. Primeiro, define o romantismo como "[...] a expressão mais recente e mais atual do belo"31, retomando o que Stendhal havia afirmado em seu Racine et Shakespeare, de 1825. Mas Baudelaire acrescenta sobre a sensibilidade romântica: “[...] intimidade,

\footnotetext{
29 “[...] qui occupe chaque printemps les colonnes ou les feuilletons des journaux et se présente sous la forme de brochures aux montres des libraires." Claude Pichois na notice da obra Critique d'art. In: Charles Baudelaire, Critique d'art, 2011, p. 479.

30 “Le public se fait-il bien une idée de la difficulté qu'il y a à modeler avec de la couleur? La difficulté est double [...], trouver d'abord la logique des ombres et de la lumière, ensuite la justesse et l'harmonie du ton." Charles Baudelaire, Critique d'art, 2011, p. 15.

31 “[...] l'expression la plus récente, la plus actuelle du beau." Ibidem, p. 80.
} 
espiritualidade, cor, aspiração ao infinito, expressas por todos os meios que contêm as artes" ${ }^{\prime 2}$, prosseguindo em relação à cor:

[...] o romantismo é filho do Norte, e o Norte é colorista; os sonhos e as feitiçarias são filhos da bruma [...]. Por outro lado, o Sul é naturalista, pois a natureza é lá tão bela e tão clara que o homem, não tendo nada a desejar, não encontra nada de mais belo a inventar do que aquilo que vê ${ }^{33}$.

De sensibilidades fundadas no espaço geográfico, está proposto o embate estético entre os coloristes românticos e os dessinateurs clássicos, voltados estes a um realismo. Desde já, Baudelaire se alia ao gosto moderno, às relativizações do belo que irão caracterizar tanto a sua obra poética quanto a sua reflexão estética posterior.

Apresenta, em seguida, uma teoria da cor, a qual possui três elementos básicos: “[...] a harmonia, a melodia e o contraponto" 34 . O contraponto se refere à combinação de tons quentes e frios; a harmonia se faz no processo desse acordo, e concerne aos vários âmbitos da combinação de cores numa obra. Por fim, a melodia é

[...] a unidade na cor, ou a cor geral. A melodia quer uma conclusão; é um conjunto onde todos os efeitos concorrem a um efeito geral [...]. A maior parte dos nossos jovens coloristas carecem de melodia. A maneira certa de saber se um quadro é melodioso é observá-lo de uma distância suficiente

\footnotetext{
32 “[...] intimité, spiritualité, couleur, aspiration vers l'infini, exprimés par tous les moyens que contiennent les arts." Ibidem, p. 81.

33 “[...] le romantisme est fils du Nord, et le Nord est coloriste; les rêves et les féeries sont enfants de la brume [...]. En revanche le Midi est naturaliste, car la nature y est si belle et si claire, que l'homme, n'ayant rien à désirer, ne trouve rien de plus beau à inventer que ce qu'il voit." Ibidem. 34 “[...] l'harmonie, la mélodie et le contrepoint." Ibidem, p. 83.
} 
para não ver nem o assunto, nem as linhas. Se é melodioso, ele já tem um sentido, ele já ocupou um lugar no repertório das lembranças ${ }^{35}$.

Léxico ligado à música, à sonoridade, além de ser um dos três elementos na teoria da cor, a melodia é o nível mais amplo na escala da composição pictórica, a qual parte do detalhe minucioso - contraponto -, passa pela harmonia e, finalmente, conclui em unidade. Além do aspecto hierárquico, a melodia está intimamente ligada à memória: a natureza visual de um quadro somente ocupará a lembrança na condição de evocar melodias. Assim, já no desenvolvimento preliminar de uma justificação técnica para a crítica no Salon de 1846, Baudelaire propõe um olhar sinestésico, a correspondência entre pintura e música. Vale reforçar que uma tal transposição só pode ocorrer através da cor, ou seja, na arte do pintor colorista, moderno, romântico.

Após expor a sua teoria, Baudelaire revela a fonte dessa reflexão em E. T. A. Hoffmann (1776-1822), escritor romântico alemão: "Ignoro se algum analogista estabeleceu solidamente uma gama completa das cores e dos sentimentos, mas lembro-me de uma passagem de Hoffmann que exprime perfeitamente a minha ideia" ${ }^{36}$. Eis o excerto de Hoffmann transcrito no texto do Salon:

35 “[...] l'unité dans la couleur, ou la couleur générale. La mélodie veut une conclusion; c'est un ensemble où tous les effets concourent à un effet général. [...] La plupart de nos jeunes coloristes manquent de mélodie. La bonne manière de savoir si un tableau est mélodieux est de le regarder d'assez loin pour n'en comprendre ni le sujet ni les lignes. S'il est mélodieux, il a déjà un sens, et il a déjà pris sa place dans le répertoire des souvenirs." Ibidem, p. 85.

36 "J'ignore si quelque analogiste a établi solidement une gamme complète des couleurs et des sentiments, mais je me rappelle un passage d'Hoffmann qui exprime parfaitement mon idée." Ibidem. 
Não é somente em sonho ou no rápido delírio que precede o sonho, é ainda acordado, quando escuto música, que encontro uma analogia e uma reunião íntima entre as cores, os sons e os perfumes. Parece-me que todas essas coisas foram provocadas por um mesmo raio de luz, e que devem se reunir em um maravilhoso concerto. $\mathrm{O}$ odor dos cuidados marrons e vermelhos produz sobretudo um efeito mágico em minha pessoa. Ele me faz cair num profundo devaneio, e escuto, então, ao longe, os sons graves e profundos do oboé ${ }^{37} \cdot{ }^{38}$

Analogia íntima entre cores, sons, perfumes; unidade num mesmo concerto; escuta longínqua, amplitude espacial e profundidade: estamos diante da linguagem simbólica e da transposição dos sentidos que propõe o soneto "Correspondances". O oboé, aliás, consta no verso "Leve como os oboés, verdes como as pradarias" ${ }^{39}$ do primeiro terceto. A escolha lexical marca um possível intertexto. Mais tarde, no ensaio De l'Idéal artificiel - le Haschinsch (Revue contemporaine, 1958) e no artigo sobre Victor Hugo (Revue fantaisiste, 1861), será citado o filósofo sueco Emanuel Swedenborg (1688-1772) e a sua teoria das correspondências, cujas premissas são semelhantes às observações de Hoffmann e a qual nomeia o famoso poema.

Desde os primeiros trabalhos enquanto escritor, seja em sua crítica, em sua filosofia ou em sua poesia, Baudelaire sustenta uma estética da transposição dos

\footnotetext{
37 “Ce n'est pas seulement en rêve, et dans le léger délire qui précède le sommeil, c'est encore éveillé, lorsque j'entends de la musique, que je trouve une analogie et une réunion intime entre les couleurs, les sons et les parfums. Il me semble que toutes ces choses ont été engendrées par un même rayon de lumière, et qu'elles doivent se réunir dans un merveilleux concert. L'odeur des soucis bruns et rouges produit surtout un effet magique sur ma personne. Elle me fait tomber dans une profonde rêverie, et j'entends alors comme dans le lointain les sons graves et profonds du hautbois." Ibidem.

${ }^{38}$ A notice das notas explica que o trecho de Hoffmann encontra-se no tomo XIX dos Contes et fantaisies, traduzidos por Loève-Veimars na França, edição de 1832.

39 "Doux comme les hautbois, verts comme les prairies." Charles Baudelaire, Les Fleurs du mal, 2012, p. 33.
} 
sentidos, explicitamente declarada a influência da sensibilidade romântica, mesmo que a reformule e substitua, ao final de sua obra, coração por imaginação, romantismo por modernidade.

\subsection{Transposições de Delacroix}

No Salon de 1845, Baudelaire já havia estabelecido a oposição entre coloristes e dessinateurs, atribuindo àqueles a qualidade da harmonia, mas não fez aí um aprofundamento teórico que os distinguisse tão claramente quanto no texto de 1846. Também não há, em sua publicação de estreia, uma teoria da cor apresentando o elemento hierárquico da melodia. No entanto, ao comentar sobre o quadro Le sultan du Maroc entoure de sa garde et de ses officiers, questiona: “Alguém já desenvolveu, de fato, em algum tempo, uma maior amabilidade musical? Veronese foi alguma vez mais fantástico? Alguém já fez cantar, sobre uma tela, melodias mais caprichosas?" ${ }^{40}$. A sinestesia evocando musicalidade em obra pictórica já estava presente no crítico estreante.

A transposição entre pintura e literatura também figura na publicação ao descrever o quadro La Madeleine dans le désert: "Ninguém, a menos que a veja, pode imaginar o quanto o artista colocou de poesia íntima, misteriosa e romântica nessa simples cabeça" ${ }^{41}$. A poesia, o romantismo e o mistério testemunham, segundo Baudelaire, o progresso do pintor enquanto harmonista.

\footnotetext{
40 "En effet, déploya-t-on jamais en aucun temps une plus grande coquetterie musicale? Véronèse fut-il jamais plus féérique? Fit-on jamais chanter sur une toile de plus capricieuses mélodies?" Charles Baudelaire, Critique d'art, 2011, p. 17.

41 “Nul, à moins de la voir, ne peut imaginer ce que l'artiste a mis de poésie intime, mystérieuse et romantique dans cette simple tête." Ibidem, p. 15.
} 
Delacroix, em ambos os textos de 1845 e 1846, é o primeiro artista a ser comentado, e uma tal organização não responde à disposição das obras para os visitantes no salão físico, tal como ocorria normalmente nas versões textuais do evento. A ordem, em Baudelaire, é uma questão de preferência, do modelo estético personificado no grande colorista.

Para compreender mais claramente a centralidade desse modelo, analisemos os comentários sobre outros artistas no primeiro salão. Se os quadros de Delacroix conduzem a inúmeros empregos de sinestesia no texto do crítico, tais figuras de linguagem não são dispensadas em relação a outros artistas. Sobre uma pintura de tema africano de Horace Vernet, Baudelaire diz que é "[...] mais fria que um belo dia de inverno" 42 . De um quadro de William Haussoullier, artista jovem e promissor, é afirmado que “[...] esta pintura tem fé - ela tem a fé de sua beleza - é uma pintura absoluta, convencida, que grita: eu quero, eu quero ser bela"43. A figura de linguagem não é propriamente uma sinestesia, e sim de uma prosopopeia, mas testemunha o estilo poético do crítico, que personificaria a natureza em "Correspondances". A respeito dos quadros de Robert Fleury, observa-se que "O espectador usufrui do esforço, e os olhos bebem suor"44, buscando expressar a dedicação do artista como ponto positivo, sendo possível, através dos nossos olhos, beber o seu suor. Já a pintura de Planet é algo “[...] acariciador para os olhos" 45 .

\footnotetext{
42 “[...] plus froide qu'une belle journée d'hiver." Ibidem, p. 17.

43 “[...] cette peinture a la foi - elle a la foi de sa beauté - c'est de la peinture absolue, convaincue, qui crie: je veux, je veux être belle." Ibidem, p. 20.

44 “Le spectateur jouit de l'effort et l'œil boit la sueur." Ibidem, p. 23.

45 “[...] caressant pour les yeux." Ibidem, p. 31.
} 
Apesar de todas essas sinestesias e transportes de sentido empregadas na apreciação de outros pintores, é fundamental observar que nenhum deles atinge um outro nível de correspondência: aquele da transposição das artes. Além de Delacroix, artista algum tem sucesso em pintar música e poesia na crítica integral do Salon de 1845. Suas obras são, certamente, elogiadas de outras maneiras, com adjetivos efetivamente positivos, com descrições entusiasmadas da pluma do crítico, mas, além do grande nome que abre as reflexões de Baudelaire, nenhum outro inspira sons ou literatura com a harmonia das cores.

Em certos momentos, entretanto, temos a impressão de que alguns chegam à sinestesia superior da transposição das artes, como no caso da Sainte Thérèse, de Planet: “As mãos são charmosas. - A atitude, natural entretanto, é tão poética quanto possível. - Este quadro respira uma volúpia excessiva"46. Mas o adjetivo poético isolado na atitude da personagem, e modulado em tanto quanto possível, não é o suficiente para fazer do quadro poesia: "Sr. Planet tem, evidentemente, talento o suficiente para fazer, em outra ocasião, um quadro completo" ${ }^{\prime 7}$. Há uma diferença considerável em relação ao substantivo poesia empregado sem maiores observações para a Madeleine au désert. Não menos importante é acrescentar que Planet é “[...] um dos muito raros alunos de Delacroix que brilham por algumas das qualidades do mestre"48: a atenção especial do crítico e a inspiração poética são justificadas.

\footnotetext{
46 “Les mains sont charmantes. - L'attitude, naturelle pourtant, est aussi poétique que possible. Ce tableau respire une volupté excessive." Ibidem.

${ }^{47}$ "M. Planet a évidemment assez de talent pour faire une autre fois un tableau complet."Ibidem. 48 “[...] un des rares élèves de Delacroix qui brillent par quelques-unes des qualités du maître."Ibidem.
} 
Outro pintor que parece atingir a transposição da linguagem artística com sua pintura é o paisagista Flers, cuja crítica é introduzida com dois versos de uma canção tradicional da Normandia. Baudelaire prossegue: "Eis o que cantaram por muito tempo todas as telas de Sr. Flers" ${ }^{\prime 4}$. Telas que cantam, eis uma evidente transposição da pintura para a música. No entanto, o crítico prossegue: "É porque, na verdade, todas essas paisagens eram poéticas e davam vontade de conhecer esses eternos e altos verdes que ele expressava muito bem" ${ }^{50}$. Nesse caso, a transposição artística é dada pelo assunto da pintura, pela representação de uma paisagem natural e cultural de uma localidade, não pela harmonia das cores ou pela técnica empregada. Apesar de Baudelaire apreciar Flers, não é em sua qualidade de colorista que se encontra a transposição da linguagem artística, como é o caso em Delacroix. A superioridade é inquestionável: "Sr. Delacroix é, decididamente, o pintor mais original dos tempos antigos e dos tempos modernos"

No Salon de 1846, além da apresentação de sua teoria da cor, cujos elementos se encontram inteiramente nas qualidades do mestre da pintura romântica, Baudelaire também propõe uma longa retrospectiva das exposições de Delacroix nos salões anteriores. Reúne comentários elogiosos de críticos das diferentes épocas, um verdadeiro trabalho de pesquisa que legitima a hegemonia do pintor. O poeta acaba sendo breve nas considerações relativas aos quadros expostos naquele ano, preferindo resumir características gerais da obra, como a

\footnotetext{
49 “Voilà ce qu'ont chanté longtemps toutes les toiles de M. Flers." Ibidem, p. 52.

50 “'C'est qu'en effet tous ces paysages étaient poétiques, et donnaient l'envie de connaître ces éternelles et grasses verdures qu'ils exprimaient si bien." Ibidem.

51 “M. Delacroix est décidément le peintre le plus original des temps anciens et des temps modernes."Ibidem, p. 13.
} 
melancolia e o mistério presentes em Dante et Virgile (Salão de 1822), nos Massacres de Scio (Salão de 1824), nas Femmes d'Alger (Salão de 1834), entre outros:

Essa altiva e séria melancolia brilha com uma explosão morna, até mesmo em sua cor, larga, simples, abundante em massas harmônicas, como a de todos os grandes coloristas, mas sofredora e profunda como uma melodia de Weber ${ }^{52}$.

A melodia referida, de acordo com a teoria da cor desenvolvida por Baudelaire, confirma-nos tanto o anúncio do poeta simbolista quanto a presença de todas as obras listadas na memória do crítico apaixonado.

\section{Considerações finais}

A obra de Charles Baudelaire é extensa, compreende uma reflexão estética e filosófica posicionada além do universo da poesia e, no entanto, parece inseparável da criação poética, essa linguagem que libera a expressão. Nem a escrita do crítico, nem a do ensaísta, nem mesmo a do poeta permitem o enquadramento nos limites de um desses gêneros apenas: antes, elas se complementam - e se respondem - uma à outra. Se os artistas que Baudelaire aprecia não podem ser definidos como artistas simplesmente, a sua própria figura obriga um ponto de partida transdisciplinar para todo estudo que explore as suas vias de reflexão e a sua produção.

52 "Cette haute et sérieuse mélancolie brille d'un éclat morne, même dans sa couleur, large, simple, abondante en masses harmoniques, comme celle de tous les grands coloristes, mais plaintive et profonde comme une mélodie de Weber."Ibidem, p. 100. 
Esperamos ter esboçado, no presente trabalho, a complexidade da obra de Baudelaire, e como a noção das correspondências, analogias e mais transposições da linguagem são embrionárias nessa dada complexidade, presente desde os primeiros anos de sua atividade de escritor. Ainda, esperamos ter evidenciado como a figura de Eugène Delacroix, especialmente, ilustra as buscas do grande autor desde a primeira fase, admiração e modelo que persistem até os últimos escritos.

O trabalho convida, é certo, a uma análise mais aprofundada do corpus aqui estabelecido, além de expor a necessidade de uma mais ampla seleção de textos de Baudelaire, a fim de confirmar com maior clareza e rigor o que foi sustentado.

\section{Referências}

ASSELINEAU, Charles. Charles Baudelaire, sa vie et son œuvre. Paris: Alphonse Lemerre, 1869.

BAUDELAIRE, Charles. Critique d'art. Paris: Gallimard, 2011.

BAUDELAIRE, Charles. Edgar Poe, sa vie et ses œuvres. In: POE, Edgar. Histoires extraordinaires (Nouv. éd.). Paris: M. Lévy frères, 1875. p. VII-XXXI. Disponível em: https://gallica.bnf.fr/ark:/12148/bpt6k2029183. Acesso em: 25 set. 2019.

BAUDELAIRE, Charles. Les Fleurs du mal. Paris: Pocket, 2012.

BAUDELAIRE, Charles. Théophile Gautier. Paris: Poulet-Malassis et de Broise, 1859. Disponível em: https://gallica.bnf.fr/ark:/12148/bpt6k113893z. Acesso em: 02 out. 2019. 
BÉGUIN, Albert. L'Âme romantique et le rêve. Paris: Le Livre de Poche, 1993.

BOYER, Philippe. Le romantisme allemand. Paris: M.A. Éditions, 1985.

CHATEAUBRIAND, F. -R. Génie du christianisme. Paris: Garnier Frères, 1828.

DIAZ, José-Luis. L'autonomisation de la littérature (1760-1860). Littérature, n. 124, Histoires littéraires, p. 7-22, dez. 2001. Disponível em: https://www.persee.fr/doc/litt_0047-4800_2001_num_124_4_1727. Acesso em: 16 out. 2019.

FRIEDRICH, Hugo. Estrutura da lírica moderna: da metade do século XIX a meados do século XX. São Paulo: Duas Cidades, 1978.

GUYAUX, André. Le Paris de Baudelaire. Paris: Éditions Alexandrines, 2017.

HUGO, Victor. Les Contemplations. Paris: Gallimard, 2010.

LEMAITRE, Henri. La Poésie depuis Baudelaire. Paris: Armand Colin, 1965.

MITTERAND, Henri. Littérature :Textes \& documents XVIIe siècle. Paris: Nathan, 1987.

PIA, Pascal. Baudelaire. Paris: Éditions du Seuil, 1995.

RAMOND, Charles. Les Philosophies et la Nature au XVIIe siècle. In: GODDARD, Jean-Christophe. La Nature: approches philosophiques. Paris: Vrin, 2002. p. 63-90.

RAYMOND, Marcel. De Baudelaire au Surréalisme. Paris: Librairie José Corti, 1940. ROUSSEAU, Jean-Jacques, Les Rêveries du promeneur solitaire. Genebra, 1782. Disponível em: https://gallica.bnf.fr/ark:/12148/bpt6k9618103m. Acesso em: 03 out. 2019.

VIGNY, Alfred de. Chatterton. Paris: Garnier-Flammarion, 1968. 
WAGNER, Richard. Euvres en prose de Richard Wagner. Paris: C. Delagrave, 1913.

\section{Referência para citação deste artigo}

DARDE, Augusto. Correspondências e sinestesias quando Baudelaire aprecia Delacroix. Revista PHILIA | Filosofia, Literatura \& Arte, Porto Alegre, volume 2, número 1, p. 115 - 143, junho de 2020. 